\title{
Phase 1 pharmacokinetic study of the oral pan-AKT inhibitor MK-2206 in Japanese patients with advanced solid tumors
}

\author{
Toshihiko Doi ${ }^{1} \cdot$ Kenji Tamura $^{2} \cdot$ Yuko Tanabe $^{2} \cdot$ Kan Yonemori $^{2} \cdot$ Takayuki Yoshino $^{1} \cdot$ \\ Nozomu Fuse ${ }^{1} \cdot$ Makoto Kodaira $^{2} \cdot$ Hideaki Bando ${ }^{1} \cdot$ Kazuo Noguchi $^{4}$. \\ Takashi Shimamoto $^{4} \cdot$ Atsushi Ohtsu $^{3}$
}

Received: 21 May 2015 / Accepted: 12 June 2015 / Published online: 24 June 2015

(C) The Author(s) 2015. This article is published with open access at Springerlink.com

\begin{abstract}
Purpose MK-2206 is an oral, highly selective inhibitor of AKT. The safety, tolerability, pharmacokinetics (PK), and anti-tumor activity of MK-2206 was evaluated in Japanese patients with advanced solid tumors.

Methods Patients received a single oral dose of MK-2206 according to an every other day (QOD) dosing schedule or a once weekly (QW) dosing schedule in repeating 28-day treatment cycles, with a 7-day rest after only the first cycle. The dose-limiting toxicities (DLTs) were evaluated during Cycle 1. Full PK sampling was performed during Cycle 1.

Results Twenty-four patients were treated at $45 \mathrm{mg}$ $(n=3)$ or $60 \mathrm{mg}(n=9)$ QOD or at $135 \mathrm{mg}(n=3)$ or $200 \mathrm{mg}(n=9) \mathrm{QW}$. One patient experienced a DLT at $60 \mathrm{mg}$ QOD, and three patients experienced DLTs at $200 \mathrm{mg}$ QW. No DLTs were observed at $45 \mathrm{mg}$ QOD or at $135 \mathrm{mg}$ QW. The DLTs included mucosal inflammation, hyponatremia, face edema, erythema multiforme, and hyperglycemia. Common adverse events related to MK-2206 included rash, an elevated insulin c-peptide level, stomatitis, pyrexia, eosinophilia, leukopenia, and hyperglycemia. PK differences in MK-2206 exposure were observed
\end{abstract}

Toshihiko Doi

tdoi@east.ncc.go.jp

1 National Cancer Center Hospital East, 6-5-1, Kashiwanoha, Kashiwa, Chiba 277-8577, Japan

2 National Cancer Center Hospital, 5-1-1, Tsukiji, Chuo-ku, Tokyo 104-0045, Japan

3 Exploratory Oncology Research \& Clinical Trial Center, National Cancer Center, 6-5-1, Kashiwanoha, Kashiwa, Chiba 277-8577, Japan

4 MSD K.K., Kitanomaru Square, 1-13-12, Kudan-kita, Chiyoda-ku, Tokyo 102-8667, Japan between Japanese patients and non-Japanese patients. The higher exposure in Japanese patients was likely caused by the relatively lower weight of Japanese patients versus non-Japanese patients. No tumor responses were observed, but six patients exhibited stable disease lasting longer than 4 months.

Conclusions MK-2206 has an acceptable safety profile in Japanese patients with advanced solid tumors and warrants further investigation.

Keywords MK-2206 · pan-AKT inhibitor · Pharmacokinetics $\cdot$ Phase I study $\cdot$ Skin toxicity

\section{Introduction}

AKT, also known as a protein kinase $\mathrm{B}(\mathrm{PKB})$, is a serine-threonine kinase that exists in three different isoforms: AKT1, AKT2, and AKT3 [1]. AKT is a key regulator of the phosphatidylinositol 3-kinase (PI3K)/AKT/mammalian target of rapamycin (mTOR) signaling pathway and is important for promoting cell survival and inhibiting apoptosis [1]. AKT is frequently activated in many human solid tumors as a consequence of overexpression or activating mutations of receptor tyrosine kinases, PI3K and Ras, the inactivation of tumor suppressor PTEN, and the amplification or mutation of AKT itself [1]. Thus, AKT is a crucial component of the PI3K/AKT/mTOR signaling pathway and is considered an attractive target for the development of new anticancer drugs.

MK-2206 is an oral, highly selective inhibitor of AKT that binds at a site in the pleckstrin homology $(\mathrm{PH})$ domain, distinct from the ATP-binding pocket, resulting in a conformational change that prevents the localization of AKT to the plasma membrane and its subsequent activation [2]. 
MK-2206 inhibited purified recombinant AKT isoforms, AKT1, AKT2, and AKT3, with an in vitro $50 \%$ inhibitory concentration [IC50] of 8,12 , and $65 \mathrm{nM}$, respectively [3]. In several cancer cell lines, MK-2206 potently inhibited AKT1 kinase activity (IC50 $\approx 20 \mathrm{nM}$ ) and blocked the AKT2 and AKT3 activities by two to sixfold less potently [4]. In in vivo preclinical models, MK-2206 showed antitumor activity as a single agent and enhanced anti-tumor activity in combination with standard chemotherapeutic agents or molecular targeted drugs [5].

A first-in-human phase 1 study was conducted to determine the maximum tolerated dose (MTD) of MK-2206 in non-Japanese patients with advanced solid tumors using an every other day (QOD) dosing schedule. The MTD for the QOD dosing schedule was $60 \mathrm{mg} / \mathrm{day}$, based on safety and biomarker data. One of $20(5.0 \%)$ non-Japanese patients at $60 \mathrm{mg}$ QOD experienced a DLT (grade 3 skin rash). The dose-limiting toxicities (DLTs) included skin rash and stomatitis. The most common drug-related adverse events included skin rash, nausea, pruritus, hyperglycemia, and diarrhea [6]. In view of the long terminal elimination halflife values of $60-80 \mathrm{~h}$, a once weekly (QW) dosing schedule has also been pursued [7, 8]. The MTD for the QW dosing schedule was established at $200 \mathrm{mg} /$ day. Four of 17 (23.5\%) non-Japanese patients at $200 \mathrm{mg}$ QW experienced DLTs (grade 3 skin rash in three patients; grade 3 dermatitis acneiform in one patient). Significant AKT pathway blockade was observed with both continuous QOD and intermittent QW dosing of MK-2206 in serially obtained tumor and platelet-rich plasma [8].

In the present study, the safety, tolerability, and PK of MK-2206 in Japanese patients with advanced solid tumors were investigated using the QOD and QW dosing schedules. The tumor response to MK-2206 was also evaluated as an exploratory objective.

\section{Materials and methods}

\section{Patient eligibility}

This study was conducted based on the Declaration of Helsinki and the Guidelines for the Clinical Evaluation Methods of Anti-Cancer Drugs in Japan (Japanese Ministry of Health, Labour, and Welfare notification, dated 1 November 2005). The study was approved by the institutional review board of each study site.

The main eligibility criteria were as follows: histologically (or cytologically) confirmed diagnosis of locally advanced or metastatic solid tumors that had failed to respond to standard therapy or for which no standard therapy exists; a patient age of 20 years or older; an Eastern
Cooperative Oncology Group performance status of 0 or 1 ; adequate hematologic, hepatic, and renal functions; and a hemoglobin A1c (HbA1c) level of $8 \%$ or less. The exclusion criteria included the use of chemotherapy, radiotherapy, or biological therapy within 4 weeks prior to enrollment; primary or unstable central nervous system metastasis; and symptomatic ascites or pleural effusion requiring treatment. All the patients provided informed consent, and the study was conducted in accordance with current Good Clinical Practice standards. This study was registered at ClinicalTrials.gov as NCT01071018.

\section{Study design and evaluation}

This study was an open-label, non-randomized, multicenter phase 1 study of MK-2206 in Japanese patients with locally advanced or metastatic solid tumors. This study was designed to investigate the safety and tolerability, PK, and anti-tumor activity of MK-2206 when administered according to either a QOD or QW dosing schedule.

MK-2206 was administered as an oral formulation at a dose of 45 or $60 \mathrm{mg}$ QOD or at a dose of 135 or $200 \mathrm{mg}$ QW. Patients took MK-2206 orally at least $2 \mathrm{~h}$ before or $2 \mathrm{~h}$ after the intake of food or a meal. Treatment was continued until disease progression or the occurrence of an unacceptable toxicity.

Patients received oral MK-2206 in repeating 28-day treatment cycles, with a 1-week rest after only the first cycle. The 28 days of Cycle 1 were regarded as the DLT evaluation period. A minimum of three and up to nine patients were enrolled at each dose level based on the toxicity probability intervals [9]. In the DLT assessments, if 0 of the 3 patients or $\leq 3$ of the 9 patients had a DLT at the dose level, the dose level was considered to be tolerable.

Adverse events were graded using the National Cancer Institute Common Terminology Criteria for Adverse Events, version 3.0. DLT was defined as any of the following occurring during Cycle 1 of treatment: grade 4 neutropenia lasting for $\geq 7$ days in duration; grade 3 or 4 neutropenia with a fever $>38.5{ }^{\circ} \mathrm{C}$ and/or infection requiring antibiotic or anti-fungal treatment; grade 4 thrombocytopenia; or grade 3 or 4 non-hematologic toxicity, except for inadequately treated grade 3 diarrhea, grade 3 nausea and vomiting, rash, hyperglycemia, grade 3 elevated transaminases of $\leq 1$ week in duration, and inadequately treated hypersensitivity reactions; any drug-related adverse event leading to a dose modification of MK-2206; unresolved drug-related adverse events regardless of grade that lasted for 2 weeks or more from the date of the next scheduled treatment; persistent increases in the QTc interval (QTc $>60 \mathrm{~ms}$ from baseline and/or $>500 \mathrm{~ms}$ ); and clinically significant bradycardia. 
The anti-tumor activity was evaluated at baseline and every 6 weeks according to the Response Evaluation Criteria In Solid Tumors (RECIST), version 1.0.

\section{Pharmacokinetics}

Blood samples for the QOD dosing schedule were collected for PK analyses just before and 2, 4, 6, 10, 24, and $48 \mathrm{~h}$ after MK-2206 dosing on days 1 and 27 of Cycle 1. After the final dose of MK-2206 during Cycle 1, blood samples were drawn 96,144, and $192 \mathrm{~h}$ postdose during the 1-week rest period. Samples were also drawn directly before MK-2206 treatment on days 7, 15, and 21. Blood samples for the QW dosing schedule were collected for PK analyses just before and 2, 4, 6, 10, 24, 48, and $96 \mathrm{~h}$ after MK-2206 dosing on days 1 and 22 of Cycle 1. After the final dose of MK-2206 in Cycle 1, blood samples were drawn 168 and $240 \mathrm{~h}$ postdose during the 1-week rest period. Samples were also drawn directly before MK-2206 treatment on days 8 and 15 . The blood samples were centrifuged, and the plasma was separated and stored at $-20{ }^{\circ} \mathrm{C}$. The plasma concentrations were analyzed using high-performance liquid chromatography with tandem mass spectroscopy (HPLC-MS/MS) at Merck Research Labs, West Point, PA. Validation data revealed an adequate accuracy, precision, and specificity of the HPLC-MS/MS assay used in this study.

\section{Results}

\section{Patient characteristics}

Twenty-four Japanese patients with advanced solid tumors were enrolled and were evaluated in this study. Among the 24 patients who were treated, three patients were in the 45-mg QOD cohort, nine patients were in the 60-mg QOD cohort, three patients were in the 135-mg QW cohort, and nine patients were in the 200-mg QW cohort. The baseline characteristics of the patients are summarized in Table 1 . The age range was 38.0-71.0 years (median: 57.0 years), and the most frequent solid tumors were colorectal cancer $(25.0 \%)$ and breast cancer (16.7 \%). The median number of prior chemotherapy regimens was 3.5 (range 1.0-8.0). The median number of treatment cycles ( 1 cycle: 4 weeks) was 4.0 (range 2.0-6.0) for the 45-mg QOD cohort, 2.0 (range 1.0-12.0) for the 60-mg QOD cohort, 2.0 (range 2.0-4.0) for the 135-mg QW cohort, and 2.0 (range 1.05.0) for the 200-mg QW cohort. The patients discontinued the study treatment because of drug-related adverse events ( $n=1$, grade 2 rash), withdrawal of consent $(n=2)$, or progressive disease $(n=21)$.
Table 1 Baseline characteristics of the patients $(n=24)$

\begin{tabular}{|c|c|}
\hline Characteristics & No. \\
\hline \multicolumn{2}{|l|}{ Age (year) } \\
\hline Median & 57.0 \\
\hline Range & $38.0-71.0$ \\
\hline \multicolumn{2}{|l|}{ Sex } \\
\hline Male & 10 \\
\hline Female & 14 \\
\hline \multicolumn{2}{|l|}{ Weight (kg) } \\
\hline Median & 57.2 \\
\hline Range & $37.0-83.0$ \\
\hline \multicolumn{2}{|l|}{ ECOG Performance status } \\
\hline 0 & 16 \\
\hline 1 & 8 \\
\hline \multicolumn{2}{|l|}{ Primary tumor } \\
\hline Colorectal cancer & 6 \\
\hline Breast cancer & 4 \\
\hline Leiomyosarcoma & 3 \\
\hline Cervical cancer & 2 \\
\hline Esophageal cancer & 2 \\
\hline Gastrointestinal stromal tumor & 2 \\
\hline Others $^{\mathrm{a}}$ & 5 \\
\hline \multicolumn{2}{|l|}{ No. of prior systemic therapy } \\
\hline Median & 3.5 \\
\hline Range & $1-8$ \\
\hline
\end{tabular}

a Ovarian cancer, renal pelvis cancer, renal cancer, mediastinal tumor, and pancreatic cancer $(n=1$ each)

\section{Safety and tolerability}

The QOD dosing schedule was investigated in two cohorts receiving $45 \mathrm{mg}$ or $60 \mathrm{mg}$, and the QW schedule was investigated in two cohorts receiving 135 or $200 \mathrm{mg}$. The DLTs occurring during Cycle 1 (28 days) were evaluated. No DLTs were observed in the three patients in the $45-\mathrm{mg}$ QOD cohort. One of the nine patients in the 60-mg QOD cohort experienced a DLT (grade 3 mucosal inflammation). The time until the onset of the DLT after the start of treatment was 28 days. For the QW dosing schedule, no DLTs were observed in the 135-mg QW cohort. Three of the nine patients in the 200-mg QW cohort experienced DLTs: one patient had grade 4 hyponatremia (time until onset, 10 days), one patient had grade 3 facial edema and grade 3 erythema multiforme (time until onset: 10 days for both DLTs), and one patient had grade 3 hyperglycemia and grade 3 erythema multiforme (time until onset: 11 days for both DLTs). The skin toxicities were manageable with topical, oral, and/or intravenous steroid therapy. No treatment-related deaths occurred in this study. One patient in the 200-mg QW cohort discontinued treatment because of grade 2 rash. 
Table 2 Common adverse events related to study medications

$\begin{array}{llllllll}45 \mathrm{mg} \text { QOD }(n=3) & & & 60 \mathrm{mg} \text { QOD }(n=9) \\ \text { All grades } \quad \text { Grades 3-5 } & \text { All grades Grades 3-5 } & & \text { All grades } \quad \text { Grades 3-5 } & & \text { All grades } \quad \text { Grades 3-5 } & \text { All grades } \quad \text { Grades 3-5 }\end{array}$

Blood and lymphatic system disorders

\begin{tabular}{|c|c|c|c|c|c|c|c|c|c|}
\hline Eosinophilia & 2 & 0 & 6 & 0 & 1 & 0 & 4 & 0 & 13 \\
\hline Leukopenia & 2 & 0 & 2 & 0 & 0 & 0 & 8 & 1 & 12 \\
\hline Lymphopenia & 2 & 2 & 5 & 2 & 0 & 0 & 2 & 2 & 9 \\
\hline Neutropenia & 2 & 1 & 2 & 0 & 1 & 0 & 4 & 0 & 9 \\
\hline \multicolumn{10}{|c|}{ Gastrointestinal disorders } \\
\hline Stomatitis & 2 & 0 & 6 & 0 & 0 & 0 & 6 & 0 & 14 \\
\hline Diarrhea & 1 & 1 & 5 & 0 & 1 & 0 & 3 & 0 & 10 \\
\hline Nausea & 0 & 0 & 1 & 0 & 1 & 0 & 3 & 1 & 5 \\
\hline Vomiting & 0 & 0 & 0 & 0 & 1 & 0 & 3 & 0 & 4 \\
\hline
\end{tabular}

General disorders and administration site conditions

\begin{tabular}{|c|c|c|c|c|c|c|c|c|c|c|}
\hline Pyrexia & 1 & 0 & 7 & 0 & 0 & 0 & 5 & 0 & 13 & 0 \\
\hline Fatigue & 1 & 0 & 4 & 0 & 1 & 0 & 4 & 0 & 10 & 0 \\
\hline Localized edema & 0 & 0 & 0 & 0 & 0 & 0 & 4 & 0 & 4 & 0 \\
\hline \multicolumn{11}{|c|}{ Metabolism and nutrition disorders } \\
\hline Hyperglycemia & 1 & 0 & 3 & 0 & 2 & 0 & 6 & 2 & 12 & 2 \\
\hline $\begin{array}{l}\text { Decreased } \\
\text { appetite }\end{array}$ & 1 & 0 & 1 & 0 & 1 & 0 & 4 & 1 & 7 & 1 \\
\hline Hypernatremia & 0 & 0 & 1 & 0 & 0 & 0 & 4 & 1 & 5 & 1 \\
\hline $\begin{array}{l}\text { Hypoalbumine- } \\
\text { mia }\end{array}$ & 0 & 0 & 2 & 0 & 0 & 0 & 2 & 0 & 4 & 0 \\
\hline Hypokalemia & 0 & 0 & 1 & 0 & 1 & 0 & 2 & 0 & 4 & 0 \\
\hline \multicolumn{11}{|c|}{ Skin and subcutaneous tissue disorders } \\
\hline Rash & 3 & 0 & 9 & 1 & 2 & 0 & 6 & 0 & 20 & 1 \\
\hline Pruritus & 1 & 0 & 4 & 0 & 0 & 0 & 5 & 0 & 10 & 0 \\
\hline Dry skin & 2 & 0 & 0 & 0 & 1 & 0 & 2 & 0 & 5 & 0 \\
\hline $\begin{array}{l}\text { Erythema multi- } \\
\text { forme }\end{array}$ & 0 & 0 & 0 & 0 & 0 & 0 & 4 & 2 & 4 & 2 \\
\hline $\begin{array}{l}\text { Palmar-plantar } \\
\text { erythrodys- } \\
\text { aesthesia } \\
\text { syndrome }\end{array}$ & 1 & 0 & 1 & 0 & 0 & 0 & 2 & 0 & 4 & 0 \\
\hline \multicolumn{11}{|l|}{ Investigations } \\
\hline $\begin{array}{l}\text { Insulin c-peptide } \\
\text { increased }\end{array}$ & 2 & 0 & 7 & 0 & 2 & 0 & 5 & 0 & 16 & 0 \\
\hline $\begin{array}{l}\text { Blood creatinine } \\
\text { increased }\end{array}$ & 1 & 0 & 1 & 0 & 0 & 0 & 6 & 0 & 8 & 0 \\
\hline $\begin{array}{l}\text { Eosinophil count } \\
\text { increased }\end{array}$ & 0 & 0 & 0 & 0 & 2 & 0 & 5 & 0 & 7 & 0 \\
\hline $\begin{array}{l}\text { HbA1C } \\
\text { increased }\end{array}$ & 0 & 0 & 2 & 0 & 1 & 0 & 4 & 0 & 7 & 0 \\
\hline ALT increased & 0 & 0 & 1 & 0 & 0 & 0 & 3 & 1 & 4 & 1 \\
\hline
\end{tabular}

All grades of adverse events reported in four or more patients are listed

The common drug-related adverse events reported for all the treatment cycles in all the arms are summarized in Table 2. The most common hematological adverse events related to MK-2206 included eosinophilia (13/24; 54.2\%), leukopenia $(12 / 24 ; 50.0 \%)$, lymphopenia $(9 / 24 ; 37.5 \%)$, and neutropenia $(9 / 24 ; 37.5 \%)$. The most common non-hematological adverse events related to MK-2206 included rash $(20 / 24 ; 83.3 \%)$, an elevated insulin c-peptide level $(16 / 24 ; 66.7 \%)$, stomatitis $(14 / 24 ; 58.3 \%)$, pyrexia $(13 / 24 ; 54.2 \%)$, hyperglycemia $(12 / 24 ; 50.0 \%)$, diarrhea $(10 / 24 ; 41.7 \%)$, and an elevated blood creatinine level $(8 / 24 ; 33.3 \%)$. 


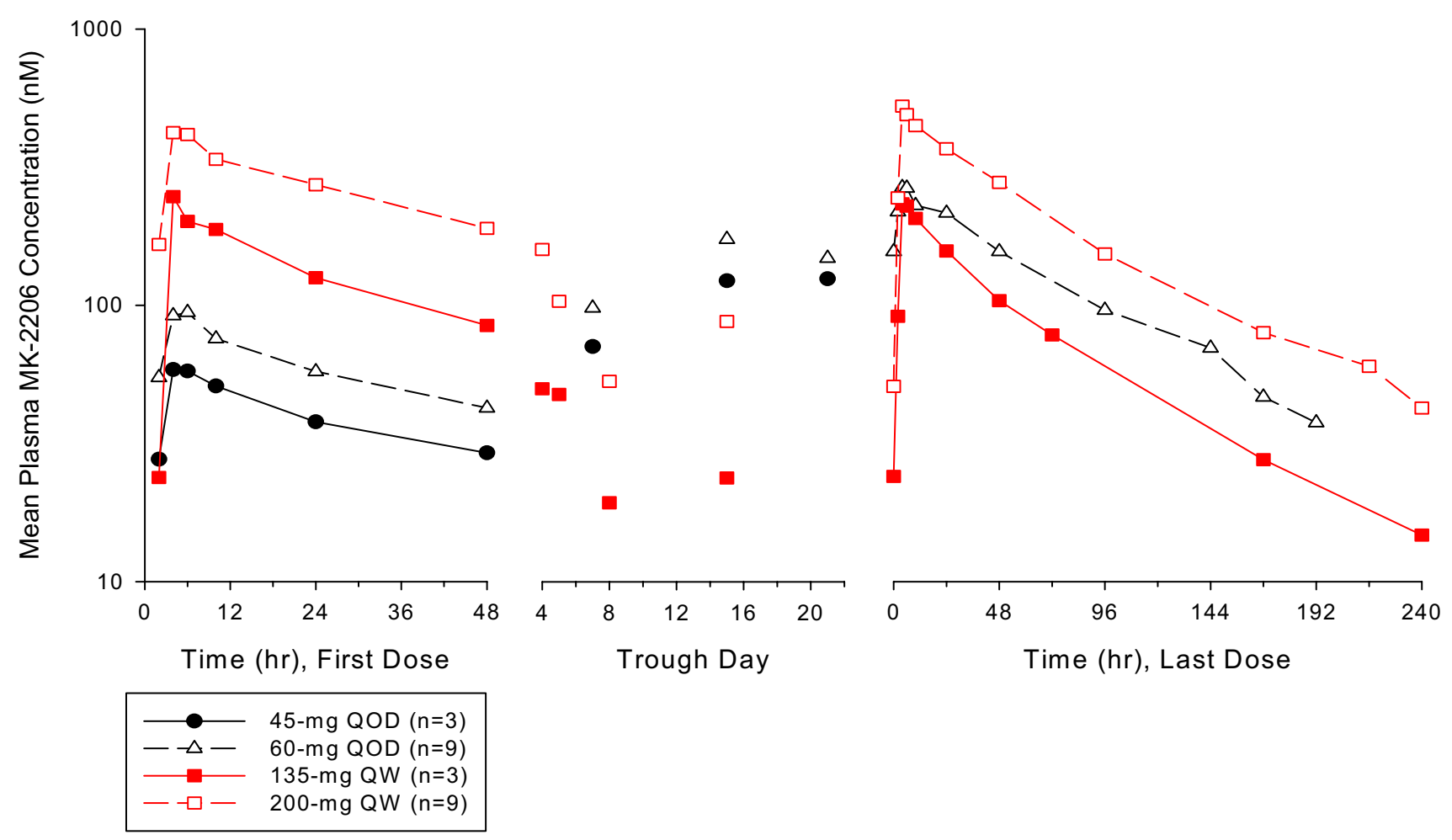

Fig. 1 Mean MK-2206 plasma concentration profiles for Japanese patients receiving multiple oral doses of 45 or $60 \mathrm{mg}$ of MK-2206 every other day (QOD) for 4 weeks or 135 or 200 mg of MK-2206 once weekly (QW) for 4 weeks (semi-log scale)

\section{Pharmacokinetic evaluation}

The mean serum concentration profiles for MK-2206 are shown in Fig. 1. Descriptive statistics for the PK parameters are given in Table 3. After the QOD dosing of MK-2206 (45 or $60 \mathrm{mg}$ ) in Japanese patients, the peak plasma concentrations were reached at a median $T_{\max }$ of 4-6 h. The harmonic mean terminal $t_{1 / 2}$ was 79.6 and $71.8 \mathrm{~h}$ after QOD dosing in the 45 - and 60 -mg cohorts, respectively. The $C_{\max }$ values on Day 27 were 214 and $277 \mathrm{nM}$, respectively, while the $\mathrm{AUC}_{0-48 \mathrm{~h}}$ values were 8490 and $9690 \mathrm{nM} \mathrm{h}$ in the 45- and 60-mg QOD cohorts, respectively. MK-2206 had accumulated at ratios of 4.59 and 3.46 on Day 27 after 45- and 60-mg QOD dosing. After the QW dosing of MK-2206 (135 and $200 \mathrm{mg}$ ) in Japanese patients, the peak plasma concentrations were reached at a median $T_{\max }$ of $4-6 \mathrm{~h}$. The harmonic mean terminal $t_{1 / 2}$ was 69.3 and $75.6 \mathrm{~h}$ after QW dosing in the 135- and 200-mg cohorts, respectively. The $C_{\max }$ values on Day 22 were 244 and $571 \mathrm{nM}$, respectively, while the $\mathrm{AUC}_{0-48 \mathrm{~h}}$ values were 12,800 and $37,600 \mathrm{nM} \mathrm{h}$ in the 135- and 200-mg QW cohorts, respectively. MK-2206 had accumulated at ratios of 1.37 and 1.62 on Day 22 after QW dosing in the 135- and 200-mg cohorts, respectively.

\section{Tumor response}

As an exploratory objective, the tumor response to MK-2206 was evaluated according to the RECIST, version 1.0. Among the 24 patients who were evaluated, no tumor responses were observed. Four patients (two with cervical cancer, one with leiomyosarcoma, and one with breast cancer) had stable disease (SD) for 4 months or longer, while two patients (one with mediastinal tumor and one with esophageal cancer) had SD for 6 months or longer.

\section{Discussion}

The primary objective of this study was to investigate the safety and tolerability of single agent MK-2206 administered as a single agent in Japanese patients with advanced solid tumors. The safety profile of MK-2206 in Japanese patients was consistent with that in non-Japanese patients. The major DLTs observed in this study were skin toxicities, which were recognized as the most common DLTs associated with MK-2206 in a previous study examining MK-2206 in non-Japanese patients [6-8]. In this study, one of nine patients experienced a DLT (mucosal inflammation) at a dose of $60 \mathrm{mg}$ QOD, and three of nine patients 
experienced DLTs (hyponatremia, facial edema, erythema multiform, and hyperglycemia) at a dose of $200 \mathrm{mg}$ QW. The skin toxicities were manageable with topical, oral, and/ or intravenous steroid therapy, and most of the patients who experienced a DLT were able to resume MK-2206 treatment after recovering from the toxicities. Most of the skin rashes were maculopapular. Maculopapular rashes have been commonly reported in association with PI3K inhibitors such as BKM120, which were generally manageable with antihistamines and topical steroid therapy, while papulopustular rashes are more frequently reported in association with the EGFR inhibitors cetuximab and erlotinib and the MEK inhibitors selumetinib and trametinib [10, 11]. The other DLTs, such as hyponatremia, hyperglycemia, and facial edema, were manageable with appropriate treatment. The common adverse events related to MK-2206 included rash, an elevated insulin c-peptide level, stomatitis, pyrexia, eosinophilia, leukopenia, and hyperglycemia. These adverse events have been previously reported in association with MK-2206 in non-Japanese patients with advanced solid tumors. Based on the above findings, we concluded that the dosing schedules for MK-2206 evaluated in this study had an acceptable safety profile in Japanese patients with advanced solid tumors.

PK differences were observed after exposure to MK-2206 in Japanese patients, compared with non-Japanese patients [8]. Consequently, the PK data were analyzed using $t$ tests and nonparametric Wilcoxon-Mann-Whitney tests because of potential differences in variance. The AUC, $C_{\max }$, and $C_{\text {trough }}$ of the patients in the 200-mg QW cohort were significantly higher $(P<0.05)$ than the corresponding values in non-Japanese patients. While the exposures in individual Japanese patients overlapped with the exposures observed in non-Japanese patients receiving MK-2206, the mean exposure values $\left(C_{\max }\right.$ and AUC) were higher (1.41.9-fold) in the 45- and 60-mg QOD and the 200-mg QW cohorts and lower (0.7-1.3) in the 135-mg QW cohort. The exposure to MK-2206 was found to vary according to body weight, and analyses of covariance (ANCOVA) models that adjusted for weight suggested that the PK differences between Japanese and non-Japanese patients can largely be attributed to inter-study weight differences, as the weights of the Japanese patients were significantly lower than those of the non-Japanese patients receiving $200 \mathrm{mg}$ of MK-2206 (Fig. 2). The apparent terminal half-life $\left(t_{1 / 2}\right)$ values were similar to those observed in non-Japanese patients (compared to $\sim 60-90 \mathrm{~h}$ in non-Japanese patients), suggesting no marked differences in the elimination rates between Japanese and non-Japanese patients. No differences in $T_{\max }$ were observed.

In this study, no tumor responses were observed, but 6 of the 24 patients $(25 \%)$ with various types of tumors experienced SD lasting longer than 4 months. MK-2206 

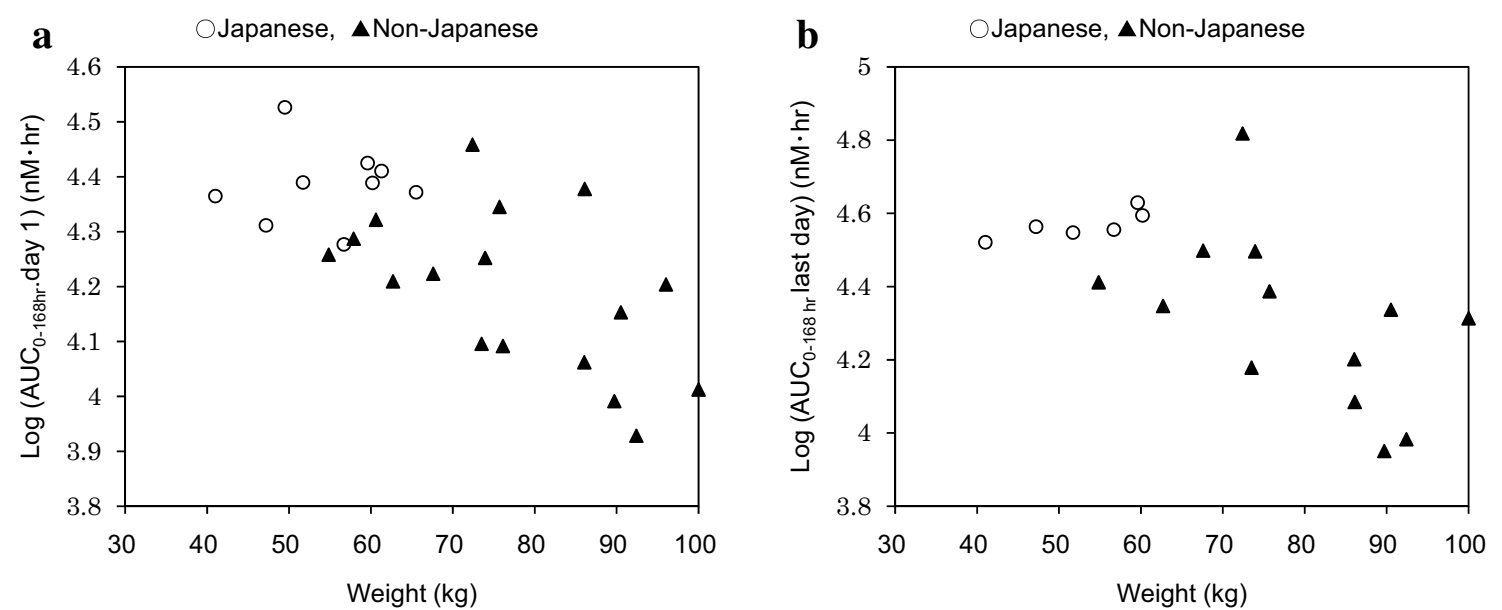

Fig. 2 Weight versus $\mathrm{AUC}_{0-168-\mathrm{h}}$ (a first dose: Day 1, b last dose: Day 22) of MK-2206 for Japanese and non-Japanese patients receiving $200 \mathrm{mg}$ of MK-2206 QW

appeared to exhibit preliminary signs of anti-tumor activity. Oncogenic PI3K pathway activation was not investigated in the patients in this study. To further characterize the antitumor activity of single agent MK-2206, a biomarker analysis examining the PI3K pathway in a clinical study with a large sample size will be necessary. PI3K pathway activation may be associated with resistance to chemotherapy and targeted therapy [12-15]. Considering the limited antitumor activity of MK-2206 monotherapy, a combination therapy containing MK-2206 may be more efficacious and should be pursued. Recently, early clinical evidence from clinical studies of MK-2206 used in combination with targeted therapy or chemotherapy has been reported $[16,17]$, and a clinical study including the combination of MK-2206 with a MEK inhibitor is presently ongoing in patients with advanced non-small-cell lung cancer (NSCLC) [18]. Thus, further investigation of the use of MK-2206 in combination therapies is also warranted in Japanese patients.

In conclusion, MK-2206 has an acceptable safety profile in Japanese patients with advanced solid tumors and warrants further investigation. PK differences were observed in the exposure of Japanese patients to MK-2206, compared with non-Japanese patients. These differences in exposure are likely due to inter-study differences in the body weights of the patients.

Acknowledgments The authors would like to thank Mikio Ishii (MSD K.K.) for PK analysis, and Shi Rong Han (MSD K.K.) for statistical analysis. Research funding was provided by MSD K.K. (Tokyo, Japan).

Open Access This article is distributed under the terms of the Creative Commons Attribution 4.0 International License (http://creativecommons.org/licenses/by/4.0/), which permits unrestricted use, distribution, and reproduction in any medium, provided you give appropriate credit to the original author(s) and the source, provide a link to the Creative Commons license, and indicate if changes were made.

\section{Compliance with ethical standards}

Conflict of interest Takashi Shimamoto and Kazuo Noguchi are employees of MSD K.K. and hold stock and stock options of Merck \& Co., Inc. The remaining authors have no potential conflicts of interest to report.

Ethical standard The study was performed in accordance with the ethical standards laid down in the 1964 Declaration of Helsinki and its later amendments. The study was approved by the institutional review board of each study site, and all the patients provided informed consent prior to their inclusion in the study.

\section{References}

1. Engelman JA (2009) Targeting PI3K signalling in cancer: opportunities, challenges and limitations. Nat Rev Cancer 9:550-562. doi:10.1038/nrc2664

2. Okuzumi T, Fiedler D, Zhang C, Gray DC, Aizenstein B, Hoffman R, Shokat KM (2009) Inhibitor hijacking of Akt activation. Nat Chem Biol 5:484-493. doi:10.1038/nchembio.183

3. Yan L (2009) MK-2206: a potent oral allosteric AKT inhibitor [abstract \#DDT01-1]. In: Proceedings of the 100th annual meeting of the American association for cancer research, Denver, CO, 18-22 Apr 2009

4. Lu W, Defeo-Jones D, Davis L et al (2009) In vitro and in vivo antitumor activities of MK-2206, a new allosteric Akt inhibitor [abstract \#3714]. In: Proceedings of the 100th annual meeting of the American association for cancer research, Denver, CO, 18-22 Apr 2009

5. Hirai H, Sootome H, Nakatsuru Y, Miyama K, Taguchi S, Tsujioka K, Ueno Y, Hatch H, Majumder PK, Pan BS, Kotani $\mathrm{H}$ (2010) MK-2206, an allosteric Akt inhibitor, enhances antitumor efficacy by standard chemotherapeutic agents or molecular targeted drugs in vitro and in vivo. Mol Cancer Ther 9:1956-1967. doi:10.1158/1535-7163.MCT-09-1012

6. Yap TA, Yan L, Patnaik A, Fearen I, Olmos D, Papadopoulos K, Baird RD, Delgado L, Taylor A, Lupinacci L, Riisnaes R, Pope 
LL, Heaton SP, Thomas G, Garrett MD, Sullivan DM, de Bono JS, Tolcher AW (2011) First-in-man clinical trial of the oral panAKT inhibitor MK-2206 in patients with advanced solid tumors. J Clin Oncol 29:4688-4695. doi:10.1200/JCO.2011.35.5263

7. Biondo A, Yap TA, Yan L et al (2011) Phase I clinical trial of an allosteric AKT inhibitor, MK-2206, using a once weekly (QW) dose regimen in patients with advanced solid tumors. J Clin Oncol 29:(suppl; abstr 3037)

8. Yap TA, Yan L, Patnaik A, Tunariu N, Biondo A, Fearen I, Papadopoulos K, Olmos D, Baird RD, Delgado LM, Tetteh E, Beckman RA, Lupinacci L, Riisnaes R, Decordova S, Heaton SP, Swales K, deSouza NM, Leach MO, Garrett MD, Sullivan DM, de Bono JS, Tolcher A (2014) Interrogating two schedules of the AKT inhibitor MK-2206 in patients with advanced solid tumors incorporating novel pharmacodynamic and functional imaging biomarkers. Clin Cancer Res 15(20):5672-5685. doi:10.1158/1078-0432

9. Ji Y, Li Y, Bekele BN (2007) Dose-finding in phase I clinical trials based on toxicity probability intervals. Clin Trials 4(3):235-244

10. Curry JL, Torres-Cabala CA, Kim KB, Tetzlaff MT, Duvic M, Tsai KY, Hong DS, Prieto VG (2014) Dermatologic toxicities to targeted cancer therapy: shared clinical and histologic adverse skin reactions. Int J Dermatol 53:376-384. doi:10.1111/ ijd. 12205

11. Bendell JC, Rodon J, Burris HA, de Jonge M, Verweij J, Birle D, Demanse D, De Buck SS, Ru QC, Peters M, Goldbrunner M, Baselga J (2012) Phase I, dose-escalation study of BKM120, an oral pan-Class I PI3K inhibitor, in patients with advanced solid tumors. J Clin Oncol 20;30(3):282-290. doi:10.1200/ JCO.2011.36.1360

12. Berns K, Horlings HM, Hennessy BT, Madiredjo M, Hijmans EM, Beelen K, Linn SC, Gonzalez-Angulo AM, Stemke-Hale K, Hauptmann M, Beijersbergen RL, Mills GB, van de Vijver MJ, Bernards R (2007) A functional genetic approach identifies the PI3K pathway as a major determinant of trastuzumab resistance in breast cancer. Cancer Cell 12:395-402
13. Eichhorn PJ, Gili M, Scaltriti M, Serra V, Guzman M, Nijkamp W, Beijersbergen RL, Valero V, Seoane J, Bernards R, Baselga J (2008) Phosphatidylinositol 3-kinase hyperactivation results in lapatinib resistance that is reversed by the mTOR/phosphatidylinositol 3-kinase inhibitor NVP-BEZ235. Cancer Res 68:9221-9230. doi:10.1158/0008-5472.CAN-08-1740

14. Brognard J, Clark AS, Ni Y, Dennis PA (2001) Akt/protein kinase $\mathrm{B}$ is constitutively active in non-small cell lung cancer cells and promotes cellular survival and resistance to chemotherapy and radiation. Cancer Res 61:3986-3997

15. Hu L, Hofmann J, Lu Y, Mills GB, Jaffe RB (2002) Inhibition of phosphatidylinositol 3'-kinase increases efficacy of paclitaxel in in vitro and in vivo ovarian cancer models. Cancer Res 62:1087-1092

16. Molife LR, Yan L, Vitfell-Rasmussen J, Zernhelt AM, Sullivan DM, Cassier PA, Chen E, Biondo A, Tetteh E, Siu LL, Patnaik A, Papadopoulos KP, de Bono JS, Tolcher AW, Minton S (2014) Phase 1 trial of the oral AKT inhibitor MK-2206 plus carboplatin/paclitaxel, docetaxel, or erlotinib in patients with advanced solid tumors. J Hematol Oncol 7:1. doi:10.1186/1756-8722-7-1

17. Hudis C, Swanton C, Janjigian YY, Lee R, Sutherland S, Lehman R, Chandarlapaty S, Hamilton N, Gajria D, Knowles J, Shah J, Shannon K, Tetteh E, Sullivan DM, Moreno C, Yan L, Han HS (2013) A phase 1 study evaluating the combination of an allosteric AKT inhibitor (MK-2206) and trastuzumab in patients with HER2-positive solid tumors. Breast Cancer Res 15:R110. doi:10.1186/bcr3577

18. Kim ES, Herbst RS, Wistuba II, Lee JJ, Blumenschein GR Jr, Tsao A, Stewart DJ, Hicks ME, Erasmus J Jr, Gupta S, Alden CM, Liu S, Tang X, Khuri FR, Tran HT, Johnson BE, Heymach JV, Mao L, Fossella F, Kies MS, Papadimitrakopoulou V, Davis SE, Lippman SM, Hong WK (2011) The BATTLE trial: personalizing therapy for lung cancer. Cancer Discov 1:44-53. doi:10.1158/2159-8274.CD-10-0010 